\title{
ANALISA SIKAP BELANJA ONLINE DAN HARGA TERHADAP KEPUTUSAN BELANJA KONSUMEN PADA EVENT FLASH SALE SHOPEE
}

\author{
Tri Widianto ${ }^{1}$, Andri Octaviani ${ }^{2}$ \\ Sekolah Tinggi Ilmu Ekonomi Adi Unggul Bhirawa Surakarta \\ Email: andry.oktavia@stie-aub.ac.id
}

\begin{abstract}
The aim of this research is to find out empirically: an analysis of the attitudes of consumer behavior in online shopping and the effect of prices on online shopping decisions in the Shopee flash sale event.

Data were collected from 130 respondents using a purposive random sampling method. Data analysis was performed through analysis of research instruments which included validity testing using product moment correlation and reliability testing using Cronbach's alpha technique; path analysis; coefficient of determination, $t$ test; $F$ test and direct and indirect influence.

The results of this study indicate that: 1) the attitude of online shopping has a positive but not significant effect on online shopping decisions, 2) the price has a positive but not significant effect on employee performance, 3) the results of the R2 Test are 0.012 or $1.2 \%$, which means that variability online shopping attitude and price variables that can be explained by the variability of decision variables in online shopping by $1.2 \%$ while the remaining $98.8 \%$ is explained by other variables not included in the regression model
\end{abstract}

Keywords: Shopping Attitudes, Prices, and Online Shopping Decisions

\begin{abstract}
ABSTRAKSI
Penelitian ini dilaksanakan bertujuan untuk mengetahui secara empiris: analisis terhadap sikap perilaku konsumen dalam belanja online dan pengaruh harga terhadap keputusan belanja online dalam event flash sale aplikasi Shopee

Data dikumpulkan dari 130 responden dengan menggunakan metode purposive random sampling. Analisis data dilakukan melalui analisis instrumen penelitian yang meliputi uji validitas menggunakan korelasi product moment dan uji reliabilitas menggunakan teknik cronbach's alpha; analisis jalur; koefisien determinasi, uji t; uji $\mathrm{F}$ dan pengaruh langsung serta tidak langsung.

Hasil penelitian ini menunjukkan bahwa: 1) sikap belanja online berpengaruh positif namun tidak signifikan terhadap keputusan belanja online, 2) harga berpengaruh positif namun tidak signifikan terhadap kinerja pegawai, 3) hasil Uji R2 didapatkan hasil sebesar 0,012 atau $1,2 \%$ yang berarti variabilitas variabel sikap belanja online dan harga yang dapat dijelaskan oleh variabilitas variabel keputusan dalam belanja online sebesar 1,2\% sedangkan sisanya 98,8\% dijelaskan oleh variabel lainnya yang tidak dimasukkan dalam model regresi
\end{abstract}

Kata kunci: Sikap Belanja, Harga, dan Keputusan Belanja Online 


\section{PENDAHULUAN}

Usaha belanja online atau toko online saat ini memang sedang menjamur dan ngetrend dikalangan penikmat dunia maya. Beragam cerita toko online dan seputar testimoni toko online pun semakin banyak dijumpai. Di Indonesia ini banyak yang sudah melakukan sistem belanja online, diantaranya yaitu market place Shopee. Online shopping atau belanja online via internet, adalah suatu proses pembelian barang atau jasa melalui internet. Sejak kehadiran internet, para pedagang telah berusaha membuat toko online dan menjual produk kepada mereka yang sering menjelajahi dunia maya (internet) melalui berbagai macam media sosial, blog, bahkan web (Alfatris, 2014).

Shopee memiliki program Flash Sale dimana penawaran produk - produk tertentu yang sudah disetujui oleh penjual dapat dijual dengan harga lebih murah dan dalam waktu yang terbatas. Bagi penjual program flash sale ini sangat menguntungkan untuk dapat meningkatkan portofolio penjualan dan mendapatkan peringkat best seller dalam produk yang mampu terjual sesuai target yang ditentukan. Sedangkan keuntungan bagi pembeli adalah dapat membeli produk dengan harga lebih murah daripada tidak melalui program flash sale. Program flash sale ini dapat mempengaruhi keputusan pembelian produk dikarenakan waktu yang mendesak dalam penawarannya serta harga yang tentunya lebih murah.

Belanja online (online shopping) adalah kegiatan jual beli atau perdagangan elektronik yang memungkinkan konsumen untuk dapat langsung membeli barang atau jasa dari penjual melalui media internet menggunakan sebuah web browser (Hardiawan,2013). Faktor yang mempengaruhi perilaku membeli menurut Kotler (2003:183-206 dalam Suhari, 2008) terdiri dari :

1) Kebudayaan yang terdiri dari : budaya, sub budaya dan kelas sosial.

2) Sosial yang terdiri dari: kelompok acuan, keluarga, peran dan status.

3) Personal yang terdiri dari: usia dan siklus hidup, pekerjaan, keadaan ekonomi, gaya hidup, kepribadian, dan konsep diri.

4) Psikologi yang terdiri dari: motivasi, persepsi, proses belajar, proses belajar, kepercayaan dan sikap.

Salah satu faktor penting konsumen tertarik untuk melakukan keputusan pembelian online, yang juga diterapkan oleh Shopee, adalah faktor harga. Konsumen sekarang ini sangat sensitif terhadap harga suatu produk. Suatu produk akan lebih mudah diterima konsumen ketika harga produk tersebut bisa dijangkau oleh konsumen. Harga dapat diukur berdasarkan kesesuaian harga dengan kualitas produk, daya saing harga, dan kesesuaian harga dengan manfaat yang diberikan produk. Kotler (1997), menyatakan bahwa harga adalah uang yang ditagihkan untuk suatu produk atau jasa, jumlah ini yang dipertukarkan konsumen untuk manfaat yang dimiliki dengan menggunakan produk atau jasa.

\section{TINJAUAN KONSEP}

\subsection{Sikap Berbelanja Online}

Seock dan Norton (2007), Rahayuningsih (2008), Prasad dan Aryasri (2009) mengemukakan bahwa sikap merupakan suatu bentuk perasaan yang 
bersifat favourable atau unfavourable. Dengan demikian, sikap pada dasarnya menunjukkan kondisi mental atau pun rasionalitas tertentu yang mencerminkan suatu pandangan pribadi mengenai suatu objek ataupun konsep. Pandangan tersebut dapat berupa pandangan yang positif (bermanfaat) dan pandangan negatif (destruktif). Kim, Ferrin, \& Rao, (2008) dan Shim, Eastlick, Lotz, \& Warrington (2001) selanjutnya menjelaskan bahwa sikap belanja online di sini merupakan faktor penyebab yang sangat penting dalam proses pengambilan keputusan pembelian online.

Sikap belanja online ini pada dasarnya merupakan respons seseorang atas kegiatan transaksi pembelian. Respons ini boleh jadi bersifat menguntungkan atau malah merugikan. Keller (1993) selanjutnya menambahan bahwa sikap terhadap belanja online adalahmencerminkan tanggapan (response) konsumen atas sistem belanja online yang ditawarkan. Kuat tidaknya keinginan sesorang untuk berbelanja secara online akan bergantung pada besar kecilnya manfaat yang diterima saat berbelanja secara online dibanding dengan risiko yang mungkin dialaminya ( $\mathrm{Yu} \& \mathrm{Wu}, 2007)$.Semakin tinggi tingkat popularitas dari sebuah website maka semakin tinggi pula kepercayaan konsumen pada website tersebut, sehingga tidak ada keraguan bagi konsumen untuk membeli secara online melalui website tersebut. Dalam pembelian online sangat rentan deng adanyapenipuan karena kedua belah pihak antara penjual dan pembeli hanya mengandalkan kepercayaan sebagai modal dalam transaksi (Ardyanto,dkk.2015)

\subsection{Pengertian Harga}

Harga merupakan satu - satunya unsur dalam bauran pemasaran yang menciptakan pendapatan, unsur lain menunjukkan biaya dan persaingan. Banyak perusahaan yang tidak mampu dalam menangani penetapan harga dengan baik. Kesalahan yang paling umum adalah penetapan yang berorientasi biaya, harga yang sering kurang direvisi, harga yang kurang bervariasi untuk produk-produk dan segmen yang berbeda.

Setelah harga ditetapkan maka harga tersebut dapat dimodifikasi agar menarik konsumen dengan cara (William dan amarto, 1997): 1) Diskon, yaitu pengurangan harga karena perbedaan jumlah produk yang dibeli, waktu pembelian dan pembayaran, 2) Harga geografis, yaitu penetapan harga karena ongkos angkut yang disampaikan kepada pembeli, 3) Harga promosi, yatu harga dibawah daftar harga yang bertujuan untuk menarik pelanggan baru yang menghabiskan persediaan, 4) Harga psikologis, yaitu pembelian harga dengan menggunakan angka ganjil atau tidak utuh dengan harapan memberi kesan murah dan 5) Harga produk baru, yaitu penetapan harga yang akan dipengaruhi oleh daur hidup suatu produk.

Harga sering jadi faktor penentu dalam pembelian, disamping tidak menutup kemungkinan faktor lannya. Harga merupakan salah satu variabel penting dalam 
pemasaran dimana harga dapat dipengaruhi konsumen dalam mengambil keputusan untuk membeli suatu produk karena berbagai alas an (Ferdinand, 2000).

\subsection{Keputusan Pembelian Online}

Keputusan pembelian merupakan kegiatan individu yang secara langsung terlibat dalam pengambilan keputusan untuk melakukan pembelian terhadap produk yang ditawarkan oleh penjual. Pengertian keputusan pembelian, menurut Kotler \& Armstrong (2001) adalah tahap dalam proses pengambilan keputusan pembeli di mana konsumen benar-benar membeli.

Belanja online adalah bentuk perdagangan elektronik (e-commerce) yang digunakan pada transaksi business- to-business (B2B) dan business-toconsumer(B2C). Menurut Deavaj et al. (2003), Keputusan membeli secara online dipengaruhi oleh: 1) Efisiensi untuk pencarian termasuk waktu cepat, mudah dalam penggunaan, dan usaha pencarian mudah, 2) Value yaitu harga bersaing dan kualitas baik, 3) Interaksi yaitu Informasi, keamanan, load time, dan navigasi. Kemudahan dalam mencari informasi tergantung dari layout halaman web. Jika layout cukup jelas, waktu yang diperlukan untuk searching dapat dipersingkat. Usaha untuk searching lebih mudah. Sehingga efisiensi meningkat. Informasi pada halaman web dihubungkan dengan beberapa komponen teks atau grafis. Bagaimana dan dimana komponen akan diletakan mempengaruhi navigasi user dan interaksi antara user dengan halaman web (Deavaj et al. 2003).

\section{METODE PENELITIAN}

Data dalam penelitian ini menggunakan data primer dari responden terhadap jawaban kuesioner. Teknik pengumpulan data yang digunakan dalam penelitian ini adalah : mendatangi secara langsung responden di lapangan yang dilakukan untuk mendapat informasi atau data dari penelitian baik berupa subyek atau obyek yang bersangkutan khususnya pengguna aplikasi shopee.

Populasi dalam penelitian ini adalah Masyarakat kota Solo yang pernah melakukan transaksi/belanja online pada aplikasi Shopee dalam program flash sale. Pengambilan sample menggunakan purposive random sampling terhadap masyarakat kota Solo sebanyak 514.171 jiwa menurut data badan pusat statistic Surakarta tahun 2017. Sampel yang digunakan adalah sebanyak 130 orang yang menggunakan aplikasi Shopee.

\section{HASIL DAN PEMBAHASAN}

\section{A. Hasil Regresi Linier Berganda}

Tabel IV.11 Hasil Uji Regresi Linier Berganda

B. Coefficients

\begin{tabular}{|c|c|c|c|c|c|c|c|c|}
\hline \multirow{2}{*}{\multicolumn{2}{|c|}{ Model }} & \multicolumn{2}{|c|}{$\begin{array}{c}\text { Unstandardized } \\
\text { Coefficients }\end{array}$} & \multirow{2}{*}{$\begin{array}{c}\begin{array}{r}\text { Standardized } \\
\text { Coefficients }\end{array} \\
\text { Beta }\end{array}$} & \multirow[b]{2}{*}{$\mathrm{t}$} & \multirow[b]{2}{*}{ Sig. } & \multicolumn{2}{|c|}{ Collinearity Statistics } \\
\hline & & $\mathrm{B}$ & Std. Error & & & & Tolerance & VIF \\
\hline \multirow{2}{*}{1} & Sikap Belanja Online &, 040 &, 051 &, 078 & ,786 & ,433 & ,999 & 1,001 \\
\hline & Harga & 043 & ,103 &, 041 & ,418 & 677 & ,999 & 1,001 \\
\hline
\end{tabular}

a. Dependent Variable: Keputusan Belanja Konsumen 
Dari pengujian statistik diperoleh persamaan regresi sebagai berikut :

$$
\mathrm{Y}=\mathbf{1 4 , 4 7 1}+\mathbf{0 , 0 4 0} \mathrm{X} 1+0,043 \mathrm{X} 2
$$

Berdasarkan persamaan regresi tersebut maka dapat diinterprestasikan sebagai berikut:

1) Nilai konstanta $(\alpha)=14,471$ menunjukkan bahwa variabel Sikap Belanja Online dan Harga tetap atau konstan, maka Keputusan Pembelian Onlinepositif.

2) Nilai $\beta 1=0,040$, menunjukkan bahwa variabel Sikap Belanja Online positif dan signifikan terhadap Keputusan Pembelian Online. Apabila variabel Sikap Belanja Online ditingkatkan maka akan meningkatkan Keputusan Pembelian Online dengan asumsi variabel lainkonstan.

3) Nilai $\beta 2=0,43$, menunjukkan bahwa variabel Harga berpengaruh positif namun tidak signifikan terhadap Keputusan Pembelian Online. Apabila variabel harga ditingkatkan maka Keputusan Pembelian Online akan meningkat dengan asumsi variabel lain konstan.

\section{B. Hasil Uji T}

\section{Tabel IV.12 Hasil Uji Statistik t}

\section{Coefficients $^{\mathrm{a}}$}

\begin{tabular}{|c|c|c|c|c|c|c|c|c|}
\hline \multirow{2}{*}{\multicolumn{2}{|c|}{ Model }} & \multicolumn{2}{|c|}{$\begin{array}{c}\text { Unstandardiz ed } \\
\text { Coefficients }\end{array}$} & \multirow{2}{*}{$\begin{array}{c}\begin{array}{c}\text { Standardized } \\
\text { Coefficients }\end{array} \\
\text { Beta }\end{array}$} & \multirow[b]{2}{*}{$t$} & \multirow[b]{2}{*}{ Sig. } & \multicolumn{2}{|c|}{ Collinearity Statistics } \\
\hline & & B & Std. Error & & & & Tolerance & VIF \\
\hline \multirow[t]{6}{*}{1} & (Constant) & 1,099 & 1,793 & & ,613 & ,541 & & \\
\hline & Kemenarikan Desain &,- 050 & , 108 &,- 061 &,- 461 & 646 & ,229 & 4,363 \\
\hline & Reputasi Vendor & 142 & , 175 & 111 & 813 & ,419 & ,210 & 4,751 \\
\hline & $\begin{array}{l}\text { Pers epsi } \\
\text { Kemudahan Belanja }\end{array}$ &,- 059 & 162 &,- 051 &,- 366 & ,716 & 203 & 4,932 \\
\hline & Sikap Belanja Online & ,383 & ,064 & ,592 & 5,975 & ,000 & ,403 & 2,484 \\
\hline & Kepercayaan & ,370 & , 191 & ,252 & 1,933 & ,056 & ,233 & 4,297 \\
\hline
\end{tabular}

a. Dependent Variable: Keputusan PembelianOnline

Berdasarkan hasil uji statistik t pada tabel di atas dapat disimpulkan sebagai berikut:

1) Pengaruh Sikap Belanja Online terhadap Keputusan Pembelian Online diperoleh nilai signifikansi sebesar 0,433>0,05 menunjukkan bahwa variabel Sikap Belanja Online Tidak berpengaruh secara signifikan terhadap Keputusan Pembelian Online, sehingga hipotesis Pertama (H1) tidakterbukti.

2) Pengaruh Harga terhadap Keputusan Pembelian Online diperoleh nilai signifikansi sebesar 0,677 < 0,05 menunjukkan bahwa variabel Harga berpengaruh tidak signifikan terhadap Keputusan Pembelian Online, sehingga hipotesis kedua $\left(\mathrm{H}_{2}\right)$ tidakterbukti. 


\section{Hasil Koefisien Determinasi Parsial (Adjusted $\mathbf{R}^{\mathbf{2}}$ )}

Hasil uji Adjusted $R$ Square diperoleh hasil sebesar -0,012 menunjukkan bahwa variabel Keputusan Pembelian Online mampu dijelaskan oleh Variabel Sikap Belanja Online (X1), dan Harga (X2)sebesar 1,2\% sedangkan sisanya 98,8\% dijelaskan oleh variabel lain yang tidak termasuk dalam penelitian ini.

\section{Pembahasan}

1) Pengaruh Sikap Belanja Online (X1) terhadap Keputusan PembelianOnline.

Pengaruh Sikap belanja Online (X1) berpengaruh positif namun tidak signifikan terhadap Keputusan Pembelian Online. Hal ini dapat diartikan semakin tinggi sikap belanja online maka akan semakin meningkatkan keputusan pembelian online. Hasil penelitian berpengaruh nyata terhadap keputusanpembelianonlinemasyarakatwilayahSurakarta.Hasilpenelitianini mendukung penelitian yang telah dilakukan oleh Khristiana(2017).

2) Pengaruh Harga ( $\left.X_{2}\right)$ terhadap Keputusan PembelianOnline.

Pengaruh Harga (X2) berpengaruh positif namun tidak signifikan terhadap Keputusan Pembelian Online. Hal ini dapat diartikan semakin tinggi Harga maka akan semakin meningkatkan keputusan pembelian online.Namun hasil penelitian tidak berpengaruh nyata terhadap keputusan pembelian online masyarakatwilayahSurakarta.Hasilpenelitianinitidakmendukungpenelitian Sarwono dan Prihartono (2012).

\section{KESIMPULAN}

Berdasarkan hasil pengujian yang telah dilakukan dalam penelitian ini, maka dapat ditarik kesimpulan sebagai berikut:

1. Hasil Analisis Regresi Linier Berganda dapat diketahui bahwa:

a. Variabel Sikap Belanja Online berpengaruh positif dan tidak signifikan terhadap Keputusan PembelianOnline.

b. Variabel harga berpengaruh positif namun tidak signifikan terhadap Keputusan PembelianOnline.

2. Sikap Belanja Online merupakan variabel yang paling mempengaruhi Keputusan Pembelian Online, kemudian diikuti dengan variableharga

3. Hasil Uji F menunjukkan bahwa secara bersama-sama variabel Sikap Belanja Online, dan Harga berpengaruh signifikan terhadap Keputusan PembelianOnline.

4. Hasil uji Adjusted $R$ Square diperoleh hasil sebesar 0,012 menunjukkan bahwa variabel Keputusan Pembelian Online belum mampu dijelaskan oleh variabel Sikap Belanja Online (X1) dan Harga(X2) sebesar 1,2\% sedangkan sisanya 98,8\% dijelaskan oleh variabel lain yang tidak termasuk dalam penelitianini. 


\section{DAFTAR PUSTAKA}

Adi, R. N. (2013). Analisis faktor-faktor yang me-mengaruhi keputusanpembelian dengan sistem pre order secara online (Studi kasus pada online shopChopper Jersey).

Anwar I \& Satrio B. (2015). Pengaruh Harga Dan Kualitas Produk Terhadap Keputusan Pembelian. Jurnal Ilmu dan Riset Manajemen, Vol 4, No12.1-15.

Arikunto,S,(2010).ProsedurPenelitian:SuatuPendektanPraktik.(EdisiRevisi). Jakarta : Rineka Cipta.

Best, R. J. (2013). Market-based management, strategies for growing customer value and profitabi-lity. New Jersey: Pearson Education, Inc.

Breckler, S. J. (1984). Empirical validation of affect, behavior, and cognition as distinctcomponentsofattitude.JournalofPersonalityandSocialPsy-chology, $\quad 47$ (6),191-205.

Broekhuizen, T. \& Huizingh, E. (2009). Online pur-chase determinants: Is their effect moderated by direct experience? Management Research News, 32(5), 440-457.

Chiu, Y., Lin, C., \& Tang, L. (2005). Gender differs: Assessing a model online purchase intention in e-tail service. Journal of Service Management, 16 (5), 416-435.

Davis, F. D. (1989). Perceived usefulness, perceived ease of use, and user acceptance of information technology. MIS Quarterly, 13(2), 318-340.

Delhagen. (1997). Retailers revs up. Forester Rese-arch, 4.

Doyle, P. (2000). Value based marketing. Journal of Strategic Marketing, 8(4), 299-311.

Ghozali, Imam. (2005). Aplikasi Multivariate dengan Program SPSS. Semarang: Universitas Diponegoro.

Hair, J. F., Black, W. J., Babin, B. J., \& Anderson, R. E. (2010). Multivariate data analysis, a global perspective. New Jersey: Pearson Prentice Hall.

Herbig, P., Milewics, J., \& Golden, J. (1994). A model of reputation building and destruction. Journal of Business Research, 31(1), 23-31.

Karimuddin, A. (2012). RE: MarkPlus insight: Jum-lah pengguna internet di Indonesia capai 61 juta orang. Diunduh 1 Maret 2015 dari https://dailysocial.net/post/markplus-insight-jumlah-peng-guna-internet-di-indonesia- capai-61juta-orang.

Katawetawaraks, C. \& Cheng, L. W. (2011). Online shopper behavior: Influences of online shopping decision. Asian Journal of Business Research, 1 (2), 66-74. 
Keaveney, S. M. (1995). Customer switching beha-vior in service industries: anexploratory study. Journal of Marketing, 59(2), 71-82.

Keller, K. L. (1993). Conseptualizing, measuring and managing customer-based brand equity. Journal of Marketing, 57(1), 1-22.

Khatibi, A., Haque, A., \& Karim, K. (2006). E-com-merce: A study on internet shopping in Malaysia. Journal of Application Science, 3(6), 696-705.

Kim, M. S. \& Ahn, J. H. (2007). Management of trust in the e-market place: The role of buyer's expe-rience in the building trust. Journal of Informa-tion Technology, 22(2), 119-132.

Kim, D. J., Ferrin, D. L., \& Rao, H. R. (2008). A trust-based consumer decision- making model in electronic commerce: The role of trust, perceiv-ed risk, and their antecedents. Decision Support Systems, 44, 544-564.

Kinnear, T. \& Taylor, J. (1995). Marketing research: An applied approach. 5th Edition. New York: McGraw Hill.

Kotler, P. \& Armstong, G. (2004). Principles of mar-keting. 11th Edition. New Jersey: Pearson Prentice Hall.

Kotler, P. \& Keller, K. L. (2013). Marketing manage-ment. 14th Edition. New Jersey: Pearson Horizon.

Kunz, M. (1997). Online customer: Identifying store, product and consumer attributeswhichinfluenceshoppingontheinternet.UnpublishedDisser-tation. University of Tennessee, Knoxville,TN.

Li, D., Browne, G., \& Chau, P. (2006). An empirical investigation of website use using a commitment-based model. Decision Sciences, 37, 427-444.

Lichtenthal, J. D. \& Eliaz, S. (2003). Internet inte-gration in business marketing tactics. Industrial Marketing Management, 32(1), 3-13.

Mayer, R. C., Davis, J. H., \& Schoorman, F. D. (1995). An integrative model of organizational trust. Academy of Management Review, 20(6), 709-734.

Mukherjee, A. \& Nath, P. (2003). A Model of trust in online relationship banking. International Journal of Marketing, 21(1), 5-15.

Niazi, M. S., Haider, M. I., Islam, T., \& Rehman, S.U. (2012). The impact of corporate social responsi-bility on brand equity. European Journal of Social Sciences, 34, $520-529$.

Nucifora.(2000).Theauthenticonlineopportunity:B2Biswhatyoureallywantto be. Houson Bu-siness Journal, 30(41), 32A. 
Pavlou, P. A. \& Geffen, D. (2002). Building effective online marketplaces with institutionbasedtrust.ProceedingsofTwentyThirdInternationalCon-ference on Information Systems,667-675.

Pikkarainen, T., Pikkarainen, K., Karjaluoto, H., \& Pahnila, S. (2004). Consumer acceptance of on-line banking: An extension of the technology acceptance model. Internet Research, 14(30), $224-235$.

Prasad,C.\&Aryasri,A.(2009).Determinantsofshopperbehaviorine-tailing:An empirical analysis. Paradigm, 13(1),73-83.

Rahayuningsih,S.U.(2008).PsikologiUmum2:Si-kap(Online).Diunduh1Maret 2015 dari www.staff.gunadarma.ac.id.

Sarwono, J. \& Prihartono. (2012). Perdagangan online: Cara bisnis di internet. Jakarta: PT Media ElexKomputindo.

Schlosser,A.E.(2003).Experiencingproductsinthevirtualworld:Theroleofgoal and imagery in influencing attitudes versus purchase intention. Journal of Consumer Research, 30(2),184-198.

Seock, Y. K. \& Norton, M. (2007). Attitude toward internet web sites, online information search, and channel choices for purchasing. Journal of Fa-shion Marketing and Management, 11(4), 571-586.

Sidharta, I \& Suzanto, B. (2015). Pengaruh Kepuasan Transaksi Online Shopping dan Kepercayaan Konsumen Terhadap Sikap Serta Perilaku Konsumen Pada ECommerce. Jurnal Computech \& Bisnis, Vol 9 No 1, 23-36.

Shen, Y., Li, S., \& Demoss, M. (2012). The effect of quantitative electronic word of mouth on consu-mer perceived product quality. International Journal of Management and Marketing Re-search. 5, 19-30.

Shim, J. P., Shin, Y. B., \& Nottingham, L. (2002). Retailer web site influence on customer shop-ping: An exploratory study on key factors of customer satisfaction. Journal of the Association for Information Systems, 3, 53-76.

Shim, S., Eastlick, M. A., Lotz, S. L., \& Warrington, P. (2001). An online prepurchase intention mo-del: The role of intention to search. Journal of Retailing, 77(3), 297416.

Sobel Test Calculator. (2015). Diunduh 1 Maret 2015 dari http://quantpsy.org/ sobel/sobel.htm.

Sonja, G. K. \& Ewald, A. K. (2003). Empirical re-search in online trust: A review and critical as-sessment. International Journal of Human-Com-puter Studies, 586, 783812. 
Sugiyono, (2012). Memahami Penelitian Kualitatif.Bandung : PT.ALFABETA.

Turban, E., King, D., Lee, J., \& Viehland, D. (2004). Electronic commerce: A managerial perspective. New Jersey: Pearson Prentice Hall.

Uddin, Md. R., Lopa, N. Z., \& Oheduzzaman, Md. (2014). Factors affecting customers' buying de-cision of mobile phone: A study on Khulna City, Bangladesh. International Journal of Mana-ging Value and Supply Chain, 5(2), 21-28.

Venkatesh, V. \& Davis, F. D. (2000). A theoretical extension of the technology acceptance model: Four longitudinal field studies. Management Sci-ence, 46 (2), 186-204.

Wangenheim, F. V. \& Bayon, T. (2004). The effect of word of mouth on services switching: Measurement and moderating variables. Euro-pean Journal of Marketing, 38(9/10), 1173-1185.

Widiyanto, I \& Prasilowati S (2015). Perilaku Pembelian Melalui Internet.Journal JMK, Vol. 17, No. 2, ,109-112.

Williams, M. 2012. Relating word-of-mouth to cor-porate reputation. Public Communication Re-view, 2, 3-16.

Wolfinbarger, M. \& Gilly, M. (2003). E-tail q: Di-mensionalizing, measuring and predicting etail quality. Journal of Retailing, 27, 183-198.

$\mathrm{Wu}$, S. I. (2003). The relationship between consumer characteristics an attitude toward online shop-ping. Management Intelligence and Planning, 21 (1), 37- 44.

Xu, B. \& Yadav, S. (2003). Effect of online repute-tion services in electronic markets: A trust based empirical study. Ninth Americas Conference on Information Systems. Texas Tech University, Texas. 